\title{
Research on the Development Countermeasures of Wuhan Robot Manufacturing Industry
}

\author{
Guopei Cai ${ }^{1}$, Dong Liang ${ }^{2}$, Zhongwei Zhang, ${ }^{3,}$ \\ ${ }^{1}$ Hubei Institute of Macroeconomics, Wuhan \\ ${ }^{2}$ Jianghan University Business School, Wuhan \\ ${ }^{3}$ Jianghan University Business School, Wuhan \\ 12053501979@qq.com²925243770@qq.com³1039857158@qq.com
}

Keywords: Manufacturing; Transformation and upgrading; Wuhan robot; Industrial development; Research strategy

\begin{abstract}
With the labor shortage and the disappearance of the demographic dividend, the manufacturing profit margin is getting smaller and smaller. The manufacturing industry urgently needs transformation, upgrading and innovation, and the robot industry is an important starting point for the transformation and upgrading of the manufacturing industry. The Wuhan Robot Industry Park is a major engine for promoting regional development and a need to promote the development of the manufacturing industry. Therefore, based on the analysis of the development status of Wuhan robot industry, this paper points out that Wuhan robot industry has a series of problems in the aspects of independent innovation ability, independent brand recognition, and "production, study and research". In order to solve these problems, this paper puts forward countermeasures from the perspectives of strengthening government orientation, improving enterprise innovation ability, building independent brands, increasing the introduction of key talents and strengthening the training of key technical skills. In order to provide some help for the development of Wuhan robot manufacturing industry.
\end{abstract}

\section{Preface}

A new round of industrial revolution marked by "Industry 4.0" has arrived, and manufacturing will become the key to the country's economic competitiveness. In recent years, countries around the world have paid more and more attention to the development of manufacturing industry. Germany has proposed Industry 4.0, the United States has proposed re-industrialization, and China has also proposed the "Made in China 2025" plan. Robots are not only the key support equipment for advanced manufacturing, but also an important entry point for improving the human lifestyle. As an important part of intelligent manufacturing, the robot industry has been highly valued in Wuhan. After unremitting efforts, the robot industry in Wuhan has developed rapidly. The development of the robot industry is an important starting point for Wuhan's innovation and development strategy, as an acceleration of Wuhan's industrial transformation and upgrading. The pioneer of the scale development of "Wuhan Zhizao", as an accelerator for building a comprehensive innovation reform pilot zone, a national innovation city, and a national manufacturing innovation center, should receive the full support of the government. Whether it is an industrial robot applied in a manufacturing environment or a service robot applied in a non-manufacturing environment, its research and development and industrial application are important indicators for measuring the level of technological innovation and high-end manufacturing in a country. Vigorously developing the robot industry is of great significance for building new advantages in China's manufacturing, promoting industrial transformation and upgrading, accelerating the construction of a strong country and improving people's living standards. 


\section{Development Status of Wuhan Robot Industry}

In recent years, the manufacturing industry has continued to develop towards automation and intelligence. Industrial robots, as a typical representative of advanced technology manufacturing, are highly integrated products of mechatronics. As one of the ten major areas of "Made in China 2025 ", it is an important symbol of industrial automation and industry 4.0. Industrial robots have multi-joint robots and multiple degrees of freedom to achieve operation. They are an important way to improve production efficiency, which relieves the pressure on equipment manufacturing costs, technology and manpower to a certain extent. President Xi Jinping pointed out at the 2015 World Robotics Conference that with the continuous integration of informationization and industrialization, the intelligent industry represented by robotics technology has emerged as an important symbol of the technological innovation of the times. China will incorporate robotics and smart manufacturing into the priority areas of national science and technology innovation.

\section{The initial system of Wuhan robot industry chain construction}

After several years of development, the basic infrastructure of the robot industry in Wuhan has been gradually improved, the scale of the industry has been continuously expanded, and the industrial chain has been initially established. Wuhan robot industry is currently in the initial stage of industrialization. Wuhan Robot is the most concentrated area of industrial robots in Hubei Province, and the most concentrated production enterprises. At present, the Donghu High-tech Zone in Wuhan has initially formed the agglomeration effect of the robot industry, and has achieved remarkable results in robot integration applications in various industries such as laser, electronics, medical, and automotive. In terms of R\&D support, the Wuhan robot industry has extensively cooperated with universities and research institutions and has achieved a number of robot development results. Among them, the intelligent robots of Wuhan University of Engineering and Wuhan University have accumulated rich research in power-specific robots. The strength of Wuhan robotics companies in the development of recent years is constantly increasing. In terms of industrialization, Wuhan has backbone enterprises such as Endeavour Power and Huazhong CNC. In the downstream integrated application, it has a large number of enterprises such as Huagong Laser and Debao Electromechanical. At present, the city is engaged in more than 40 enterprises engaged in the research and development, design and manufacture of robot products and downstream integrated applications. The construction of the robot industry chain in Wuhan has been initially established.

\section{Industrial Robot Development has Made Great Progress}

The theoretical research on industrial robots in Wuhan started earlier and has strong research and development capabilities for industrial robots. The province has achieved a number of important achievements in the basic theoretical research of industrial robots, which have had an important impact in the country. In the past ten years, Huazhong University of Science and Technology has combined digital manufacturing technology, advanced electronic manufacturing technology, robotics and intelligent control to establish a theory of complex curved surface processing. The spatial geometric reasoning method of robot operation planning is proposed, and the large-blade robot "measurement-operation-processing" integrated $(3 \mathrm{M})$ grinding and polishing system is developed and applied in the fields of aerospace, energy and automobile. The research results have won the National Science and Technology Progress Award and the National Natural Science Award for many times.

At present, the level of industrial robots in Wuhan is constantly improving in product development, design, manufacturing and integration applications. It has been able to independently research and develop the series of products such as articulated robots, omnidirectional mobile controllable robots and remote transit robots, and has obtained corresponding independent property rights and key core technologies. For example, Wuhan Huachangda Intelligent Equipment Co.,Ltd. has been identified as a famous brand of Wuhan and a major scientific and technological achievement of Hubei Province. Wuhan Ende Smart Technology Co., Ltd. has completed nearly 20 kinds of end-effectors, including hydraulic, pneumatic, electric and electromagnetic driving 
methods. The rapid development of the Wuhan robot industry has provided greater capacity for the Wuhan industry while saving more labor costs.

\section{The Initial Formation of the Robot Industry Agglomeration Effect}

The robot industry is an important direction and main battlefield for the development of advanced manufacturing technologies. Planning and developing the robot and intelligent equipment industry is an important way to implement the major decisions of the provincial party committee and the provincial government to accelerate the transformation and upgrading of Hubei's industry. It is also a major measure for Wuhan to build an industrial upgrade and achieve industrial transformation and upgrading. The construction and cultivation of the Wuhan Robot Industry Base is of great significance for promoting the implementation of the pilot project of strategic emerging industries in Hubei Province, strengthening the scale of Hubei's intelligent equipment industry and promoting industrial transformation and upgrading in the province. Although the development of Wuhan's robot industry is relatively lagging behind, with the strategic layout and policy support, the East Lake High-tech Zone Robot Industrial Park has been initially formed. The Wuhan robot industry has formed a certain agglomeration effect.Through the vigorous introduction of robot leading enterprises and the active cultivation of local enterprises, Wuhan is gradually building a robot chain with complete chain, advanced technology and outstanding advantages. Guide the rational connection between production and demand, accelerate the pace of industrial robot research and development, industrial integration and application innovation, and expand the influence in the development of domestic robot industry.

\section{Problems and Bottlenecks in the Development of Wuhan Robot Industry}

In recent years, with the continuous attention of the country to China's robot industry, the Wuhan robot industry has developed rapidly. However, the Wuhan robot industry still lags behind the developed coastal areas and even some central cities. The overall scale of the company is small, lacking a leading enterprise in robotics, and has not formed a research and development center, industrial cluster, scale enterprise and well-known brands. In the market of robots, it has been facing the competitive pressure of foreign brands. In terms of manufacturing process and equipment, it is impossible to produce high-precision, high-speed and high-efficiency key components, and there is no breakthrough in the overall core technology. There are few industrial robots with independent intellectual property rights. At present, the technical strength of robot research and manufacturing in Wuhan is relatively dispersed, and production, learning, and research are alone, there is no unified organization standard, and basic technology sharing cannot be achieved. The key technologies rely on imports and imitations. The medium and low-end production capacity is too high, and the high-end production capacity is insufficient. Some industries have structural overcapacity.

\section{Insufficient capacity for independent innovation, key core components are subject to people}

Although the Wuhan robot industry has basically mastered the related technologies of industrial robots such as ontology design and manufacturing, control system software and hardware, and motion planning, the overall technical level is still far from the developed cities such as Shanghai and Guangzhou. Core components such as precision reducers, servo motors, servo drives, and controllers cannot be produced by themselves, so it is difficult to compete with foreign companies for the production cost of robots. In addition, most of the robot manufacturers in Wuhan mainly rely on imitation and follow-up. The production enterprises are generally small in scale, low in independent innovation capability, low in end products and small in market share.

Wuhan robot enterprises are mainly concentrated in system Integrators and downstream applications. The core components of robots, servo motors, controllers and reducers are almost all imported. Compared with foreign companies, robot manufacturers have to purchase speed reducers at nearly four times the price, and purchase servo drives at nearly twice the price, which greatly increases the cost burden of Wuhan robot companies. Although in 2014, Wuhan Eslite Reducer Manufacturing Co., Ltd. successfully developed a robot reducer - RV reducer. However, compared 
with foreign-funded enterprises in terms of control precision, stability and product life, the gap is still obvious, and it is easy to wear and scrap. Therefore, there are few domestic robot enterprises to choose, and they are still dependent on imports.Despite the vigorous promotion of national policies, the scale of Wuhan robot manufacturers has continued to expand. However, due to the lack of key core technologies, the application of domestic robots is mainly concentrated in the general industrial field and some simple life applications, and is marginalized in the high-end market. (Data Sources: "White Paper on China's Robot Industry Development (2016))

The medium and low-end production capacity is high, and the recognition of independent brands is not high

Although Wuhan industrial robots have made great progress in recent years, Wuhan industrial robots are mainly produced in the middle and low-end products. The main production is robots for handling and loading and unloading, mostly three-axis and four-axis robots. The market for six-axis or higher-end high-end industrial robots used in high-end industries such as automobile manufacturing and welding is mainly occupied by companies in developed countries such as Japan, Europe and the United States. The domestic six-axis industrial robots account for less than $10 \%$ of the new installed robots in the country, and the competition brought by developed countries is fierce.

In addition, compared with other developed countries, China started late in robot development. Due to the late start and weak foundation, China's robot industry technology is relatively backward, and the domestic robot market is dominated by foreign companies. The current robotic industry market is dominated by Europe and Japan. The four giants ABB, KUKA and FANUC account for about $50 \%$ of the global industrial robot body. In terms of key components, more than $70 \%$ of the market share of robotic reducers is monopolized by Japanese companies. Because most business users are accustomed to using foreign brands. Especially in the automotive and electronic industries, which have the largest usage and the highest requirements on equipment quality, the main body and component products of the independent brand of Wuhan robot manufacturing industry cannot be put into the market as soon as possible, and even products with successful application experience are difficult to promote and apply.

The traditional combination of "production, study and research" is too loose, and the transformation of scientific research results is difficult

The combination of traditional "production, study and research" has played a certain role in giving play to the advantages and resources of enterprises, universities and research institutes. However, due to the different interests pursued by the three, many problems have arisen in the process of cooperation. In terms of the transformation of results, universities and research institutes often carry out scientific research only in order to obtain scientific research results, often neglecting the transformation of scientific research results into applied products, which leads to the disconnect between scientific research results and product application. Although some research and development institutions in Wuhan have many research and development achievements, most of them stay in the laboratory stage, and have not completed the transformation to market applications, and Wuhan local research institutes have not yet hatched a large-scale independent research and development robot enterprise. In addition, enterprises often neglect the development of core technologies because of the pursuit of short-term interests, resulting in the low-end of products. This loosely combined "production, study and research" directly restricts the development of Wuhan's robot industry.

\section{Wuhan robot enterprise lacks technical talents}

Although Wuhan's talent environment is in a leading position in the country. It has gathered 9 key institutions and scientific research institutions such as the Robotics Research Center of China University of Science and Technology, Huazhong University of Science and Technology, Wuhan University, Wuhan University of Technology, National CNC System Engineering Research Center, and State Key Laboratory of Digital Manufacturing Equipment and Technology. However, robot manufacturing is a complex system engineering. The $R \& D$ design, integrated application, production operation, operation and maintenance in the robot industry require a large number of top, 
high-end talents and skilled workers to support. However, at present, there are very few professional and training institutions in Wuhan universities, which are far from supporting the development of the robot industry. At this stage, Wuhan robot enterprises have a large gap in the middle-end technical talents such as electronic development, mechanical design, production assembly, and integrated application. They also lack professional talents in management, operation, and product sales. The lack of talent restricts the development of Wuhan's robot industry.

\section{Research on the Development Countermeasures of Wuhan Robot Industry}

\section{Strengthening the government's guiding role and realizing the development of Wuhan robot industry}

The development of the industry is inseparable from the expansion of market demand and government support. Through the market mechanism and the government's macro-control, the robot industry will be guided to develop in a rational and orderly manner. The prototype of the Wuhan robot industry has emerged. The main function of the government is to improve the industrial environment, establish an innovative policy system, guide and encourage enterprise innovation activities, and coordinate social forces to achieve sustainable development of the Wuhan robot industry.

In order to break through the key problem of robot core component technology, change the core components to be controlled by people. An effective government-led collaborative innovation mechanism should be established to give full play to the scientific research advantages of universities and research institutes, the application advantages of enterprises, and the transformation of scientific research results. Although the Wuhan Municipal Government has already issued relevant policies to help the development of the robot industry, the specific support policies have to be further optimized. It is necessary to formulate plans and policies that are more in line with the development rules of the robot industry and the actual needs of the bases, and further play the role of macroeconomic policies.

Enhance the innovation capability of enterprises and strengthen the research and development of key common technologies

Advanced manufacturing is an important carrier of technological innovation, the most concentrated and active area of innovation, and the fertile ground for innovation to be applied. Enhance the independent research and development innovation capability of the enterprise, promote the research and development of core technologies and key components, and strive to make breakthroughs in core patents and market applications, and realize the localization of key components and body manufacturing of robots. This is the core competitiveness of the robot industry. Actively encourage enterprises in Wuhan to establish strategic alliances with technology research and development with famous universities and research institutions, strengthen basic research and application technology development, and strive to promote the transformation and industrialization of scientific research results.

The robot enterprises with independent innovation awareness and independent intellectual property rights will be given all-round support to improve the core competitiveness of Wuhan robot enterprises. In addition, enterprises should actively seek cooperation with research institutes, and introduce or hire experts and scholars to establish internal R\&D centers or intelligent production workshops to form innovative endogenous power and achieve enterprise quality and efficiency. We will conscientiously build a company-led industrial technology research and development system, and strive to promote the collaborative innovation of various innovation entities such as industry, academia and research, and improve the original innovation capability of enterprises. Finally, we must promote the application and industrialization of results with core independent intellectual property rights, foster the development of strategic emerging industries, and enhance the overall level of innovation of Wuhan robotics enterprises.

Create a self-owned brand and broaden the application field

Due to the unfamiliarity of foreign robot companies to the local market, compared with foreign robot companies, Wuhan robot integrators have advantages in terms of channel, price and cost. 
Wuhan local robot companies can accurately grasp the characteristics of the domestic market and customer needs, but also have lower labor costs and price advantages. In this way, Wuhan robotics companies can build their own brands and use low cost to achieve personalized user needs. Most of the robot companies in Wuhan have both an ontology and an integrated business. The combination of ontology and integration can avoid many industry chain links, which creates opportunities for independent brands. A key development direction of the robot body is to enable upstream component companies and downstream system integrators to effectively integrate and open up the upstream and downstream industry chains.

The robot industry is mainly driven by the manufacturing industry. Applying the robot industry to life can effectively improve people's health and living standards, enrich people's cultural life, and improve people's living conditions. At present, the robot industry has a wide range of applications, including machinery manufacturing, pharmaceuticals, medical, home appliances and food. At present, the downstream application enterprises of the robot industry in Wuhan are mainly in the automotive field. It is impossible to rely on this field to break through the production to a large extent. Therefore, Wuhan robot enterprises should actively promote application demonstration, extend the downstream industrial chain, and expand the application field of Wuhan robot industry.

\section{Increase the introduction of key talents and strengthen the training of key technical and technical personnel}

Talent is the creator of new knowledge, the inventor of new technology, the leader and pioneer of new breakthroughs in technology, new ways of development, and the most important strategic resource for innovation. With the transformation and upgrading of the manufacturing industry and the introduction of robots, technical and skilled personnel in robot handling and maintenance also need to be resolved in time. The development of Wuhan robots is inseparable from the cultivation of talents. It encourages and encourages through laws and regulations, promotes the talent training model of production, education and research, and establishes a new mechanism for joint training of talents by schools and enterprises.

On the one hand, the introduction of key talents can strengthen local talent training. By learning from the talent policies of other advanced cities and regions, using vocational training and vocational qualification systems, we will cultivate the talents needed by Wuhan robot enterprises through actual project training. On the other hand, strengthen the introduction of external talent. Establish a network of contacts with scientific research institutions such as excellent colleges and universities across the country. Through the implementation of large-scale cooperation projects, the joint venture will cultivate multi-level technical talents from research and development, production, maintenance to system integration. In addition, you can use some channels that can communicate with overseas talents, and attract overseas talents and overseas study elites to work in Wuhan robotics enterprises with excellent salary and scientific research environment.

\section{Conclusion}

The rapid development of foreign industrial robot industry has driven the industrialization of industrial robots in China, but it also occupies many domestic markets. While the Wuhan robot industry has a wide range of application prospects and huge market potential, it has also ushered in unprecedented competitive pressures and challenges. In recent years, although China's research on the robot industry has made great progress, it has made breakthroughs in key technologies, but it still lacks breakthroughs in the overall core technology. Although it has been applied in all walks of life, imported robots account for the vast majority. The development of Wuhan's robot industry should combine its own characteristics to form its own unique development. Policy support with technological progress, technological innovation and enhanced competitiveness can fundamentally solve the dynamics and vitality of industrial development.

\section{Acknowledgement}

(WZ2017Y10) Manufacturing Industry Development Research Center on Wuhan City Circle, 
Jianghan University

\section{References}

[1] Ping Zhang,Qing Ma. Research on the status quo and countermeasures of robot industry development in the Yangtze River Delta region [J]. Science and Technology and Industry, 2018, 18 (07): 38-42.

[2] Xue Wu, Jiahe Tian. Countermeasure Research on Innovative Development of Suzhou Robot Industry[J].Journal of Southern Yangtze University(Humanities and Social Sciences), 2016,15(05):70-80.

[3] Hui Xu. Development status and suggestions of robot industry in Kunshan City [J]. China High-tech Enterprise, 2016 (27): 3-4.

[4] Wenbin Liu. Problems and Countermeasures for Promoting the Development of Guangdong Robot Industry[J]. Market Economy and Price, 2016(08): 48-52+24.

[5] Minghe Chen. Problems in the development of China's robot industry and countermeasures [J]. Science and Technology for Development, 2015 (06): 768-774.

[6] Daokui Qu. Status quo and prospect of China's robot industry development [J]. Chinese Academy of Sciences, 2015, 30 (03): 342-346+429.

[7] TingWu, Changlin Ye.Analysis of Strategic Environment for the Development of Robot Industry in Wuhu City[J].Journal of Chizhou University,2014,28(05):55-58.

[8] Yingchun Wang,Cuixiao $\mathrm{Fu}, \mathrm{Yu}$ Zhang, Yinglong Shen. Development Strategy and Countermeasures of Shanghai Robot Industry[J].Science Development,2014(07):42-46.

[9] Tianmiao Wang, Yong Tao. China's industrial robot technology status and industrialization development strategy[J]. Journal of Mechanical Engineering, 2014, 50(09): 1-13. 